\title{
An Investigation of Cool Roofing on Urban Street Canyon Air Quality
}

\author{
$\underline{\text { M. K. Naidu }}^{\text {a }}{ }^{\text {Z. F. Tian }}{ }^{\text {a }}$, P. R. Medwell ${ }^{\text {a }}$ and C. H. Birzer ${ }^{\text {a }}$ \\ ${ }^{a}$ School of Mechanical Engineering, The University of Adelaide, North Terrace, S.A. 5005, Australia \\ Email: magaesh.naidu@adelaide.edu.au
}

\begin{abstract}
The installation of cool roofing in urban areas is a practical mitigation measure to reduce the Urban Heat Island (UHI) effect and is currently being implemented in many cities around the world to reduce building cooling load demands. The UHI effect results from surface and air temperatures of urban areas being higher than rural areas due to the thermal properties of buildings and reduced vegetative cover. Examples of cool roofs are white vinyl roofs and roofs with reflective coatings. Cool roofs have high albedo (also known as solar reflectivity or solar reflectance) which helps to reflect sunlight and therefore, reduce roof temperatures. Lower roof temperatures result in lower internal temperatures within buildings and this significantly reduces their cooling load. A street canyon is an representative unit of an urban area whereby a street is flanked by two tall buildings on both sides. The aim of this study was to investigate the effect cool roofing has on the air quality within a street canyon. In this project, an idealised street canyon with a street canyon height-to-width ratio of one was created in a Computational Fluid Dynamics (CFD) model which utilises the Renormalization Group (RNG) k- $\varepsilon$ turbulence model. In order to verify the model's ability to simulate thermal effects, the CFD model was first validated against experimental results from an atmospheric diffusion wind tunnel in a study carried out by the Japanese National Institute for Environmental Studies. Then, the validated CFD model was run with two different roof temperatures to investigate the effect of a cool roofing product's cooling intensity on the street canyon. In the model, a constant area source of pollutant mass flow was generated at the bottom of the street canyon to simulate road traffic emissions. Selected air quality indicators such as Air Exchange Rate $(A C H)$, Pollutant Exchange Rate $(P C H)$ and Average Volume Mass Fraction $(\Theta)$ were then used to analyse the modelling results. The analysis indicated that the air quality within the street canyon is improved marginally as a result of cooler air entering the street canyon due to negative buoyancy generated by cool roofing.
\end{abstract}

Keywords: Cool roofing, Urban Heat Island Effect (UHI), air quality, urban street canyon, Computational Fluid Dynamics (CFD), Renormalization Group (RNG) $k$ - $\varepsilon$ turbulence model 


\section{INTRODUCTION}

The Urban Heat Island (UHI) effect results from surface and air temperatures of urban areas being higher than rural areas due to the thermal properties of buildings and reduced vegetative cover. Cool roofing is a practical mitigation measure to reduce the UHI effect. Examples of cool roofs are white vinyl roofs and roofs with reflective coatings. Cool roofs have high albedo (also known as solar reflectivity or solar reflectance) which helps to reflect sunlight and therefore, reduce roof temperatures. Lower roof temperatures result in lower internal temperatures within buildings and this significantly reduces their cooling load.

Some recent studies of cool roofing were reviewed as a part of this study. In a study by the University of Melbourne, field testing and computer modelling were used to study the effects and benefits of cool roof paints on a variety of buildings (The University of Melbourne, 2011). The results showed that the paint was highly effective in reflecting solar radiation and lowering roof surface temperatures, when compared to a standard metal roof material. In summer, the control roof (Zincalume ${ }^{\mathrm{R}}$ ) reached $68^{\circ} \mathrm{C}$ while the coolest roof in the study reached $35^{\circ} \mathrm{C}$.

Another recent study that examined a similar rooftop heat mitigation measure was by Baik et al. (2012) where the effects of building roof greening on air quality was studied. Results for a street canyon with height-to-width ratio of one was examined. A street canyon is an representative unit of an urban area whereby a street is flanked by two tall buildings on both sides. The cool air that enters the street canyon was found to affect the intensity of street canyon flow. The thermally driven downward air flow motion due to negative buoyancy combines with the expected downward wind flow strengthened vortex circulation. The strengthened street canyon flow was found to enhance pollutant dispersion and improve air quality near roads. This study focussed on absolute pollutant concentration levels and did not examine the air and pollutant exchange that occurs within the street canyon.

The thermal heating of walls and floors in street canyons has been investigated in several wind tunnel experiments (Uehara et al., 2000; Kovar-Panskus et al., 2002; Richards et al., 2006; Allegrini et al., 2012) where thermally stratified wind tunnels were utilised. However, the sole influence of heated roofs has not been examined. Sini et al. (1996) have studied the mechanical-buoyant induced flow in a street canyon and have demonstrated that wall temperature can largely influence the flow structure and vertical transport distribution. Hence, it is supected that roofs which have a lower surface temperature may produce an effect of pollutants being flushed out of a street canyon.

Xie et al. (2006) examined the mechanical-buoyant induced wind flow in an street canyon considering different aspect ratios, temperature difference, wind velocity and symmetrical and asymmetrical canyons on vortex structure and pollutant dispersion. In these studies, the Bulk Richardson number, $R_{b}$ was used to characterise thermal effects by relating the negative thermal buoyancy produced by the effect of cool roofs to the velocity of the wind flow passing above the roofs. $R_{b}$ has been used in this study to validate the CFD model with wind tunnel results.

In this paper, an idealised street canyon is studied in a Computational Fluid Dynamics (CFD) model to investigate the effect of cool roofing on the pollutant dispersion and air flow within. The maximum cooling intensity of $33^{\circ} \mathrm{C}$, detailed in a cool roofing study (The University of Melbourne, 2011), was studied. The CFD model is first validated against experimental wind tunnel results from the Japanese National Institute for Environmental Studies (Uehara et al., 2000) to to verify its ability to reproduce thermal effects using $R_{b}$. A pollutant source was then generated at the bottom of the street canyon to simulate traffic emissions. The cooling intensity generated by the cool roofing was simulated by running the CFD model with two different surface roof temperatures. The changes to the air quality are assessed by indicators such as Air Exchange Rate $(A C H)$, Pollutant Exchange Rate $(P C H)$ and Average Volume Concentration $(\Theta)$ proposed by Liu et al. (2005); Li et al. (2005); Cheng et al. (2008). The findings of this study provide a preliminary understanding of the air quality implications of cool roofing in an urban environment.

\section{Methodology}

\subsection{CFD Model}

The commercial CFD code, ANSYS FLUENT 14.0 was used to solve the steady state flow and pollutant transport in this study. The Renormalization Group (RNG) (Yakhot and Orszag, 1986) k- $\varepsilon$ turbulence model has been used, since it has been validated by other street canyon studies involving pollutant dispersion and temperature effects (Chan et al., 2002; Xie et al., 2006; Cheng et al., 2009; Baik et al., 2012). An energy 


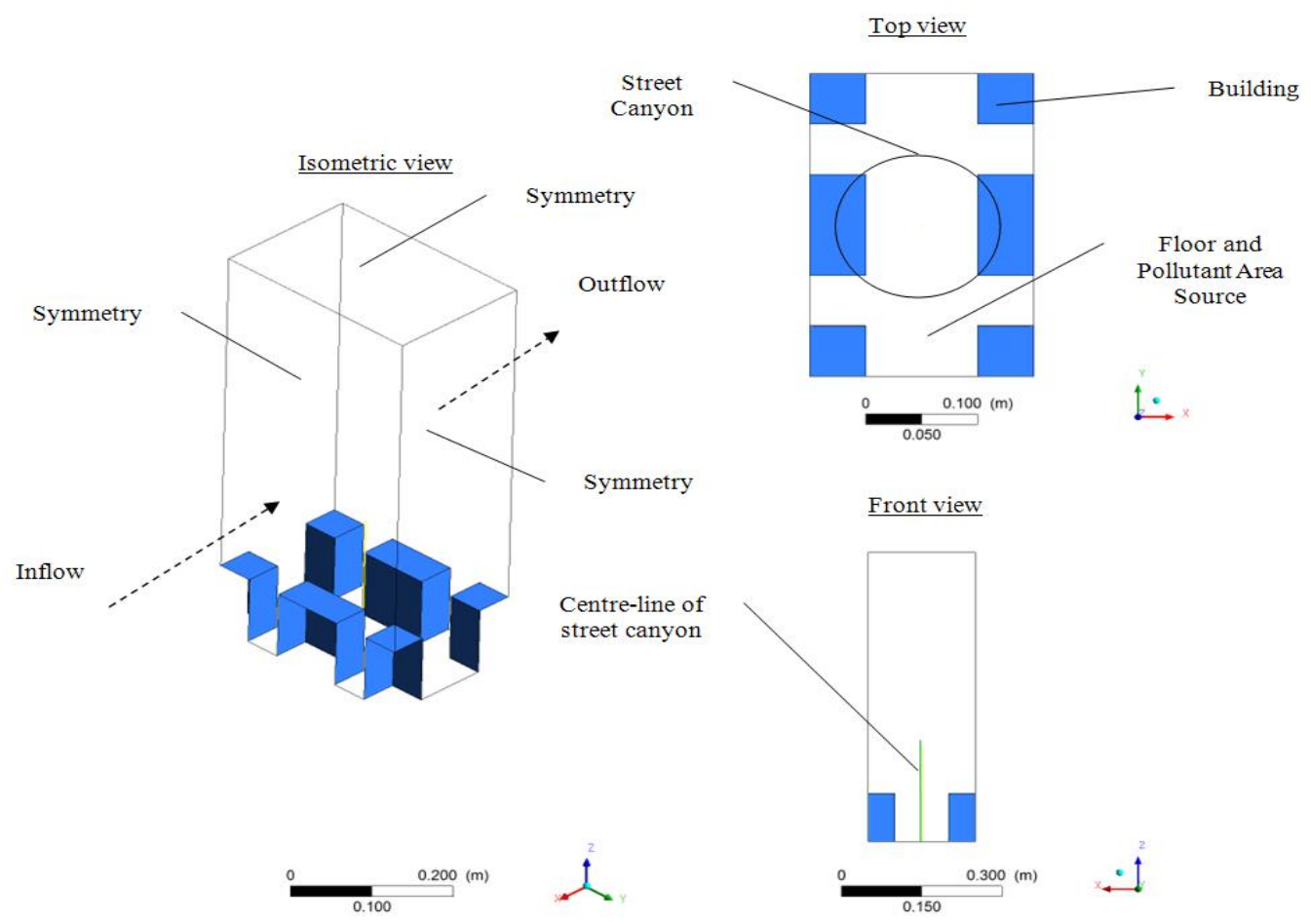

Figure 1. Computational domain

conservation equation is included to simulate thermal effects and pollutant transfer is solved by a transport equation. The computational domain used in the CFD model simulates the wind tunnel test (Uehara et al., 2000) and is shown in Figure 1. The height and width of the street canyon are set to $0.1 \mathrm{~m}$ to simulate a street canyon height-to-width ratio of one as in the wind tunnel experiment (Uehara et al., 2000). The height of the domain is $0.6 \mathrm{~m}$ from the floor and the width and the length of the domain are $0.2 \mathrm{~m}$ and $0.3 \mathrm{~m}$ respectively.

\subsection{Boundary Conditions}

Due to the computational limitations with respect to the number of cells (380 076 cells), the top of the domain was modeled as a symmetry surface. In the CFD model, the street canyon is considered to be an infinitely long street canyon and therefore, the three-dimensional domain is simplified by specifying symmetry conditions for the side surfaces of the spatial domain.

In the FLUENT CFD model, all the solid boundaries, including the roofs, floor and walls were specified as noslip walls. Enhanced wall treatment with thermal effects was employed for walls. The momentum, turbulent kinetic energy and dissipation rate were discretised using the QUICK third-order upwind scheme and the SIMPLE algorithm was used to solve the pressure-velocity coupling equations. Standard pressure equations and the Least Squares Cell based method was used for spatial discretization.

\subsection{Validation}

The CFD model was validated with the results from a study carried out by the Japanese National Institute for Environmental Studies (Uehara et al., 2000) where an atmospheric diffusion wind tunnel was used.

In order to validate the CFD model, the Bulk Richardson Number, $R_{b}$, velocity, turbulent kinectic energy and its dissipation should match that of the wind tunnel experiment (Uehara et al., 2000) as realistically as possible. The same bulk Richardson number, $R_{b}$ was used in the CFD model. The Bulk Richardson number, $R_{b}$ is defined as follows:

$$
R_{b}=\left(\frac{g h}{U_{h}^{2}}\right) \frac{T_{h}-T_{f}}{T_{a}}
$$




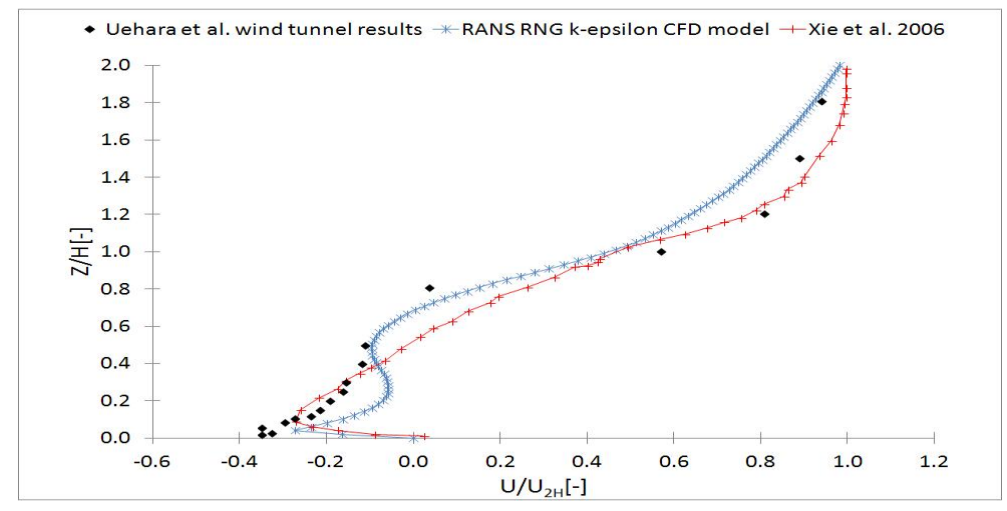

Figure 2. Horizontal velocity profile at the centre of the street canyon

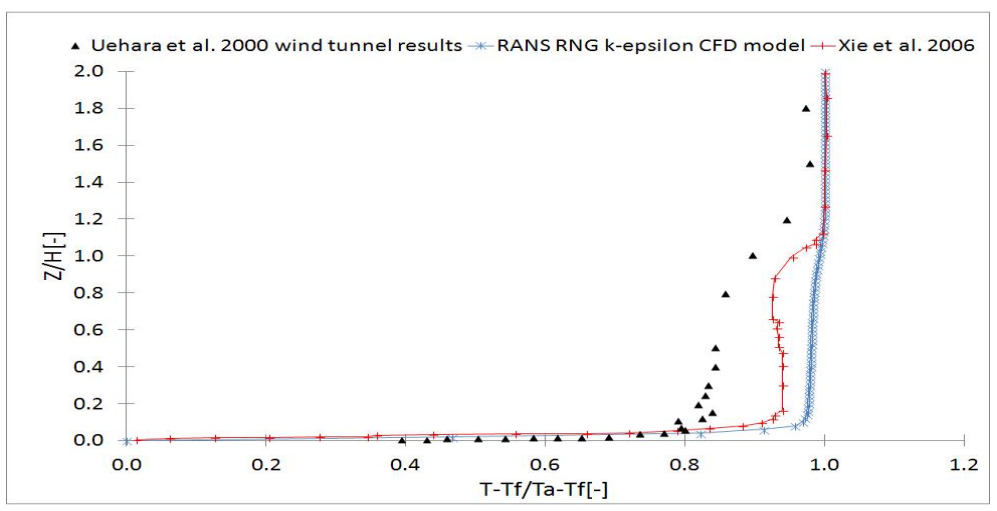

Figure 3. Potential temperature profile at the centre of the street canyon

where $h$ is the street canyon height, $g$ is gravitational acceleration, $T_{h}$ is the temperature at roof level, $T_{f}$ is the temperature at floor level, $T_{a}$ is the ambient temperature and $U_{h}$ is the streamwise velocity at roof level. The wind tunnel results for $R_{b}=-0.21$ was simulted in the CFD model. In order to simulate this value, $T_{f}$ was set to $79^{\circ} \mathrm{C}$ and $T_{a}$ was set to $20^{\circ} \mathrm{C}$.

The profile of the wind approach the street canyon to be studied in a street canyon is of particular importance. The velocity as well as the turbulent kinectic energy and its dissipation of the air flow in the CFD model studied should match that of the wind tunnel experiment as realistically as possible. With regard to accurately modelling the velocity profile, the Working Group of the Architectural Institute of Japan (Tominaga et al., 2008) recommends the use of the formulae from Richards and Hoxey (1993) for fully-developed inlet profiles of mean velocity, turbulent kinetic energy and dissipation rate under neutral stratification conditions and these formulae were used in this study.

Figures 2 and 3 compare the measured and modeled horizontal velocity and potential temperature along the vertical centerline of the street canyon. The $y$-axis, $Z / H$ of Figure 2 and Figure 3 represents the nondimensional height of the street canyon which is calculated by dividing the vertical distance, $Z$ along the centreline of the street canyon with the height of the street canyon, $H(=0.1 \mathrm{~m})$. The $\mathrm{x}$-axis, $U / U_{2 H}$ of Figure 2 is the non-dimensional horizontal velocity which is computed by dividing the horizontal velocity, $U$ along the centreline of the street canyon by the freestream velocity, $U$ at $2 H(=0.2 m)$. The $\mathrm{x}$-axis for Figure 3 is the potential temperature along the centreline of the street canyon which is computed as $\frac{T-T_{f}}{T_{a}-T_{f}}$ using the definitions of the terms provided in Equation 1.

With regard to horizontal velocity, the CFD model was found to overpredict the velocity magnitude within the street canyon while under-predicting the velocity magnitude above the street canyon. However, the general trend in velocity increase matches the wind profile of the wind tunnel experiment. Potential temperature is a key aspect as this study involves thermal effects and the model over-predicts this within the street canyon. 
Table 1. Summary of results

\begin{tabular}{|c|c|c|c|}
\hline Scenario & $A C H[-]$ & $P C H[-]$ & $\Theta[-]$ \\
\hline \hline Roof top temperature $=53^{\circ} \mathrm{C}$ (Before installation of cool roofing) & 0.00182 & $-2.81 \times 10^{-5}$ & 0.215 \\
\hline Roof top temperature $=20^{\circ} \mathrm{C}$ (After installation of cool roofing) & 0.00185 & $-2.53 \times 10^{-5}$ & 0.212 \\
\hline
\end{tabular}

However, the CFD model accurately predicts a sharp increase in potential temperature at the top of the street canyon. The surface roughness of the solid boundaries in the wind tunnel experiment is unknown and that imposes uncertainty in the CFD predictions. Also, recreating the exact wind profile from the wind tunnel in the CFD model is difficult. However, the trend observed in the temperature increase along the $\mathrm{z}$-axis was comparable to the wind tunnel results. Hence, the model used in this study is considered reliable for simulating airflow and considering thermal effects for the purpose of this study. The results also closely follow results from a similar CFD model validation exercise by Xie et al. (2006).

\subsection{Cooling Intensity Simulations}

Two CFD simulations were carried out with different roof top temperatures. In the first simulation where there is no cool roofing, the CFD model was set up with the rooftop surface temperature being at $53^{\circ} \mathrm{C}$ and the ambient temperature being at $20^{\circ} \mathrm{C}$. In the second simulation, the roof top surface temperature and the ambient temperature were set at $20^{\circ} \mathrm{C}$. The two cases simulate the implementation of cool roofing with a cooling intensity of $33^{\circ} \mathrm{C}$. This corresponds to the same maximum cooling intensity determined in summer in the cool roofing study carried out by the University of Melbourne (The University of Melbourne, 2011).

For both simulations, a constant inlet wind flow of $1.5 \mathrm{~m} / \mathrm{s}$ was used. The floor of the street canyon was treated as an area pollutant source simulating road traffic emissions. The rate of pollutant emission from the street canyon floor was an inert tracer set at $1 \mathrm{~g} / \mathrm{s}$. The results are presented in mass fractions which provide a dimensionless concentration value. The values may be converted to parts per million ( $\mathrm{ppm}$ ) or $\mu \mathrm{g} / \mathrm{m}^{3} \mathrm{using}$ the molar mass of $\mathrm{CO}$ or other typical traffic pollutants if emission rates are available.

\subsection{Air Quality Assessment}

Air quality in this study is assessed by air exchange rate $(A C H)$, pollutant exchange rate $(P C H)$, average pollutant mass fraction $(\Theta)$. $A C H$ and $P C H$ represent the rate of air and pollutant removal respectively from a street canyon. $\Theta$ represents the average concentration of pollutants from the floor to the roof of the street canyon and is provided in the dimensionless unit of mass fraction in this study. The concepts of $A C H$ and $\mathrm{PCH}$ were used by Liu et al. (2005) based on Large-Eddy Simulation (LES) to analyze the air quality in a street canyon. In view of the excessive computational resources required for LES, Li et al. (2005) used Reynolds-Averaged Navier Stokes (RANS) equations with the RNG k- $\varepsilon$ turbulence model instead to estimate $A C H$. The RANS approach was then extended to include $P C H$ and $\Theta$ by Cheng et al. (2008).

\section{RESULTS AND DISCUSSION}

A cross-sectional slice of the centre of the street canyon was used to study the velocity magnitude and the pollutant mass fraction flowing across the canyon. The results indicated that the velocity magnitude does not differ noticeably after the implementation of cool roofing. The effects of building roof greening on air quality in street canyons was investigated by Baik et al. (2012) and the time-averaged turbulent kinetic energy has been observed to increase within a street canyon when the cooling intensity increases. However, from this study, this increase was found not to cause a significant increase in the velocity magnitude in the street canyon. The vertical velocity component, $w$, was investigated at the horizontal roof line of the street canyon to understand the air exchange occuring at the top of the street canyon. A plot of vertical velocity against the horizontal width of the canyon is shown in Figure 4.

A positive $w$ denotes upward flow and it can be observed that due to a lower roof surface temperature, there is less upward air flow until $X / H=0.42$ ( $X / H=0.5$ is the middle of the canyon). This indicates the negative buoyancy effect of a cooler roof which occurs until approximately mid-canyon. Air quality analysis was carried out using the methods discussed in Section 2.5. ACH, $\mathrm{PCH}$ and $\Theta$ were computed and are presented in Table 1.

Varying the cooling intensity affects produces marginal changes to $A C H, P C H$ and $\Theta$. There is an increase in the rate of air and pollutants leaving the street canyon as described by higher $A C H$ and $P C H$ values for 


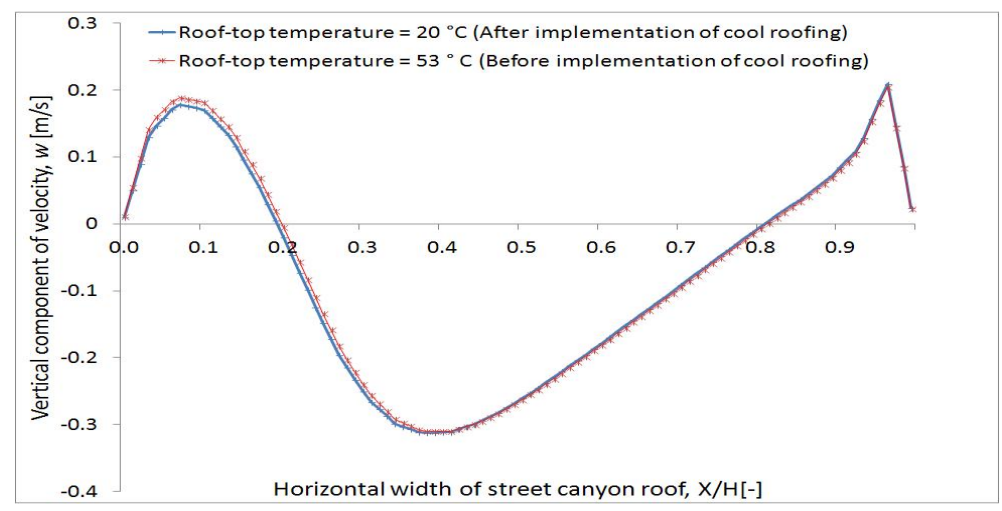

Figure 4. Vertical velocity at steet canyon rool level

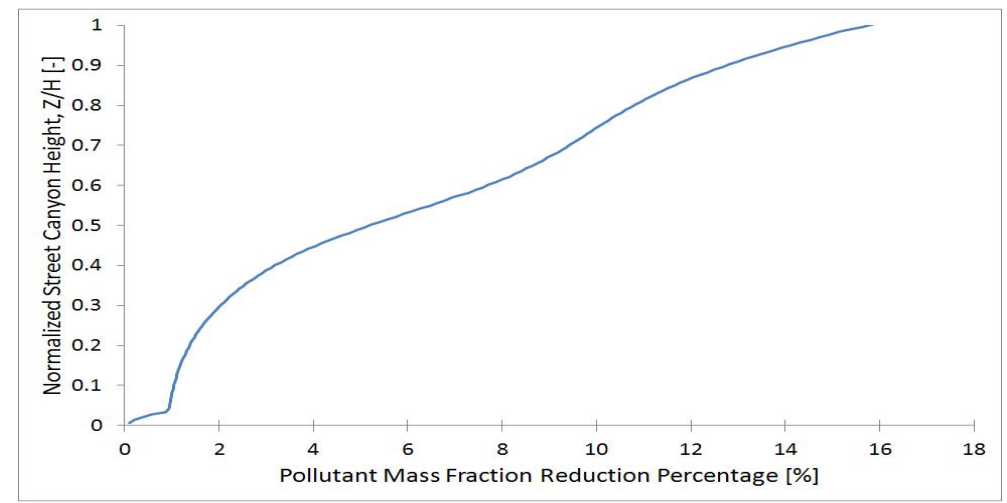

Figure 5. Pollutant Mass Fraction Reduction Percentage

the cooler roof $\left(20^{\circ} \mathrm{C}\right)$. There is also a decrease in $\Theta$ within the street canyon by $1.2 \%$. The centre line of the street canyon was examined to analyse the average pollutant mass fraction reduction along the height of the street canyon. The non-dimensional vertical height of the street canyon was plotted against the percentage of pollutant reduction in Figure 5.

A positive reduction percentage was observed and this is an indication that air quality improves within the street canyon. However, at pedestrian and car height which is approximately $Z / H=0.1$, the pollutant reduction percentage is $1.6 \%$. The magnitude of reduction is low and further analysis is required to evalute the significance of this reduction. However, it can be noted that no detrimental air quality impacts may be observed from the application of cool roofing in accordance to this study.

\section{Conclusion}

A CFD model was created to simulate a street canyon where a realistic cooling intensity was simulated to examine road traffic pollutant emissions. Cool roofing produced marginal benefits in air quality through cooler air entering the street canyon due to negative buoyancy. This was determined through an analysis of selected air quality indicators. However, it is inconclusive if these benefits are substantial for promoting cool roofing for reasons other than building cooling load reduction benefits. No detrimental air quality effects were observed due to cool roofing in this study.

While non-reactive pollutants were investigated in this study, studying reactive traffic pollutants such as $\mathrm{NO}_{2}$ by coupling a CFD model with a $\mathrm{NO}-\mathrm{NO}_{2}-\mathrm{O}_{3}$ photochemistry model is a potential study area. Different approach velocities to analyse variations in flow and pollutant dispersion and the effect of different cooling intensities are recommended to be examined in future studies. 


\section{REFERENCES}

Allegrini, J., V. Dorer, T. Defraeye, and J. Carmeliet (2012). An adaptive temperature wall function for mixed convective flows at exterior surfaces of buildings in street canyons. Building and Environment 49, 55-66.

Baik, J.-J., K.-H. Kwak, S.-B. Park, and Y.-H. Ryu (2012). Effects of building roof greening on air quality in street canyons. Atmospheric Environment 61, 48 - 55.

Chan, T., G. Dong, C. Leung, C. Cheung, and W. Hung (2002). Validation of a two-dimensional pollutant dispersion model in an isolated street canyon. Atmospheric Environment 36(5), 861 - 872.

Cheng, W., C.-H. Liu, and D. Y. Leung (2008). Computational formulation for the evaluation of street canyon ventilation and pollutant removal performance. Atmospheric Environment 42(40), 9041 - 9051.

Cheng, W., C.-H. Liu, and D. Y. Leung (2009). On the correlation of air and pollutant exchange for street canyons in combined wind-buoyancy-driven flow. Atmospheric Environment 43(24), 3682 - 3690.

Kovar-Panskus, A., L. Moulinneuf, E. Savory, A. Abdelqari, J.-F. Sini, J.-M. Rosant, A. Robins, and N. Toy (2002). A Wind Tunnel Investigation of the Influence of Solar-Induced Wall-Heating on the Flow Regime within a Simulated Urban Street Canyon. Water, Air and Soil Pollution: Focus 2(5-6), 555-571.

Li, X.-X., C.-H. Liu, and D. Y. Leung (2005). Development of a model for the determination of air exchange rates for street canyons. Atmospheric Environment 39(38), 7285 - 7296.

Liu, C.-H., D. Y. C. Leung, and M. C. Barth (2005). On the prediction of air and pollutant exchange rates in street canyons of different aspect ratios using large-eddy simulation. Atmospheric Environment 39(9), $1567-1574$.

Richards, K., M. Schatzmann, and B. Leitl (2006). Wind tunnel experiments modelling the thermal effects within the vicinity of a single block building with leeward wall heating. Journal of Wind Engineering and Industrial Aerodynamics 94(8), 621-636.

Richards, P. and R. Hoxey (1993). Appropriate boundary conditions for computational wind engineering models using the $\mathrm{k}-\varepsilon$ turbulence model. Journal of Wind Engineering and Industrial Aerodynamics 46-47, 145 - 153. Proceedings of the 1st International on Computational Wind Engineering.

Sini, J.-F., S. Anquetin, and P. G. Mestayer (1996). Pollutant dispersion and thermal effects in urban street canyons. Atmospheric Environment 30(15), 2659-2677.

The University of Melbourne (2011, September). Cool roofs: City of melbourne research report. Technical report, The University of Melbourne.

Tominaga, Y., A. Mochida, R. Yoshie, H. Kataoka, T. Nozu, M. Yoshikawa, and T. Shirasawa (2008). AIJ guidelines for practical applications of CFD to pedestrian wind environment around buildings. Journal of Wind Engineering and Industrial Aerodynamics 96(10-11), 1749-1761.

Uehara, K., S. Murakami, S. Oikawa, and S. Wakamatsu (2000). Wind tunnel experiments on how thermal stratification affects flow in and above urban street canyons. Atmospheric Environment 34(10), 1553-1562.

Xie, X., C.-H. Liu, D. Y. C. Leung, and M. K. H. Leung (2006). Characteristics of air exchange in a street canyon with ground heating. Atmospheric Environment 40(33), 6396-6409.

Yakhot, V. and S. A. Orszag (1986). Renormalization group analysis of turbulence. I. basic theory. Journal of Scientific Computing 1(1), 3-51. 